\title{
Transmission of Batrachochytrium dendrobatidis within and between amphibian life stages
}

\author{
Lara J. Rachowicz*, Vance T. Vredenburg \\ Department of Integrative Biology, University of California, Berkeley, California 94720-3140, USA
}

\begin{abstract}
Chytridiomycosis is an emerging infectious disease caused by the chytrid fungus Batrachochytrium dendrobatidis, which has been implicated in amphibian declines worldwide. The mountain yellow-legged frog Rana muscosa is a declining amphibian species that can be infected by $B$. dendrobatidis; however, transmission between conspecifics has not been documented. Here, we present experimental evidence that $R$. muscosa tadpoles can be infected by fungal zoospores and that they can transmit infection to each other and to postmetamorphic animals. We compared several techniques for detecting $B$. dendrobatidis transmission and found that histology with serial sectioning was able to detect infection before cytology or visual inspections. We also show that $R$. muscosa tadpoles appear healthy with $B$. dendrobatidis infection, while postmetamorphic animals experience mortality. In addition, we provide guidelines for visually detecting $B$. dendrobatidis in $R$. muscosa tadpoles, which may be useful in other affected species. Field surveys of infected and uninfected populations verify this identification technique.
\end{abstract}

KEY WORDS: Amphibian decline $\cdot$ Chytridiomycosis $\cdot$ Emerging infectious disease $\cdot$ Rana muscosa Tadpole

Resale or republication not permitted without written consent of the publisher

\section{INTRODUCTION}

Infectious disease, alone and in synergy with other factors, has been implicated in the decline of amphibian populations worldwide (Blaustein et al. 1994, Laurance et al. 1996, Berger et al. 1998). Although many pathogens have been observed in amphibians (reviewed by Wright \& Whitaker 2001), the chytrid fungus Batrachochytrium dendrobatidis has recently been associated with severe declines and extinctions of amphibians in Australia (Berger et al. 1998), South America (Young et al. 2001), Central America (Lips 1998), Mexico (Lips et al. 2004), USA (Bradley et al. 2002, Muths et al. 2003), and Europe (Bosch et al. 2001). The disease associated with this fungus, chytridiomycosis, has recently appeared in amphibian populations and is considered an emerging infectious disease (Daszak et al. 1999). Many of the reported outbreaks have occurred in protected habitats without obvious human impacts (Berger et al. 1998, Bosch et al.
2001, Muths et al. 2003), as is the case for the mountain yellow-legged frog Rana muscosa (Fellers et al. 2001).

Rana muscosa exists almost entirely on protected federal lands, occurring in montane areas around the Los Angeles Basin in southern California and in the Sierra Nevada range in California and Nevada, USA (Zweifel 1955). The populations in southern California are listed as federally endangered, and Sierra Nevada populations are in steep decline. Although this species was once the most commonly encountered vertebrate in high elevation aquatic ecosystems of the Sierra Nevada (Grinnell \& Storer 1924, Zweifel 1955), it has become increasingly rare over the past several decades (Jennings 1996). The best-documented cause of declines in $R$. muscosa is the introduction of nonnative fish (Bradford 1989, Bradford et al. 1993, Knapp \& Matthews 2000, Vredenburg 2004), but chytridiomycosis presents a new threat (Fellers et al. 2001).

Mass mortalities have occurred in postmetamorphic animals infected with Batrachochytrium dendrobatidis 
in numerous anuran species (Berger et al. 1998, Daszak et al. 1999, Bosch et al. 2001, Bradley et al. 2002); however, no mortality has been reported in infected anuran larvae. Although B. dendrobatidis has been identified in amphibian species and amphibians have been experimentally infected from laboratoryreared $B$. dendrobatidis zoospores (the mode of transmission) (Berger et al. 1999, Nichols et al. 2001), studies documenting transmission within and between life stages are lacking.

Our focal species, Rana muscosa, has an unusually long tadpole stage, lasting 2 to $4 \mathrm{yr}$ prior to metamorphosis (Zweifel 1955). Historically, R. muscosa tadpoles of various age-classes formed extremely dense aggregations in the shallow areas of high-altitude lakes during summer days (Grinnell \& Storer 1924). Although the species is in decline, dense aggregations of tadpoles and postmetamorphic animals have recently been observed along several lake shorelines (Vredenburg 2004). Knowing whether transmission occurs between tadpoles and from tadpoles to postmetamorphic animals will help us predict the spread and effects of chytridiomycosis.

Batrachochytrium dendrobatidis is found in the keratinized structures of infected postmetamorphic animals (skin) and tadpoles (mouthparts) (Berger et al. 1998, Pessier et al. 1999, Fellers et al. 2001). The oral discs of most tadpoles contain keratinized jaw sheaths and tooth rows that are normally heavily pigmented (Altig \& McDiarmid 1999). The current non-lethal method of identifying infection in tadpoles is inspecting mouthpart pigmentation for abnormalities (Berger et al. 1999, Lips 1999, Fellers et al. 2001, Vredenburg \& Summers 2001, Bradley et al. 2002). In larval Rana muscosa, a lack of pigment of these structures is strongly associated with chytridiomycosis (Fellers et al. 2001). Pigment abnormalities in tadpole mouthparts associated with chytridiomycosis also occur in other species outside of the United States (Lips 1999, Lips et al. 2003, 2004). However, there is potential for erroneous identification of chytridiomycosis based on mouthpart abnormalities because depigmentation of mouthparts is also associated with metamorphosis (Gosner 1960), exposure to chemical contaminants (Hayes et al. 1997, Rowe et al. 1998), and low temperatures (Rachowicz 2002).

The objectives of this study were (1) to test the possibility of conspecific transmission between Rana muscosa tadpoles and from tadpoles to postmetamorphic animals using controlled laboratory experiments, (2) to observe the effects of infection on larval and postmetamorphic stages, and (3) to infect $R$. muscosa tadpoles with laboratory-reared Batrachochytrium dendrobatidis zoospores and document the resulting pattern of pigment loss caused by $B$. dendrobatidis over time.
This pattern was contrasted with the pattern of pigment loss observed with exposure to low temperature conditions (based on Rachowicz 2002). Field surveys were conducted to verify patterns observed in the laboratory.

\section{MATERIALS AND METHODS}

Detection of Batrachochytrium dendrobatidis. We compared several identification techniques to detect chytridiomycosis in Rana muscosa. To detect chytridiomycosis in live animals, we used visual inspection and cytology. Visual inspection consisted of examining the pigmentation of tadpole jaw sheaths and tooth rows with a 10× hand lens (Fellers et al. 2001). We estimated the percent of the upper and lower beak lengths that were pigmented (0 to $100 \%$ ), classified the width of each beak as thinly or thickly pigmented, and classified the tooth rows as fully pigmented, partially depigmented, or fully depigmented. Cytology consisted of scraping epithelial cells off the skin of postmetamorphic animals (Berger et al. 1998) or the jaw sheaths of tadpoles with the dull side of a sterile scalpel blade, mounting cells on a slide with a drop of water, and microscopically examining the cells for the presence of $B$. dendrobatidis sporangia. Sporangia are spherical bodies ( 7 to $15 \mu \mathrm{m}$ diam.) where zoospores are produced (Longcore et al. 1999, Pessier et al. 1999).

Additionally, we used histology ('standard' and 'serial sectioning') and culturing to detect Batrachochytrium dendrobatidis. For histological examination, all animals were euthanized with MS-222 and fixed in $10 \%$ neutral buffered formalin. We embedded mouthparts in paraffin, sectioned at $8 \mu \mathrm{m}$, and stained with hematoxylin and eosin (H\&E). For standard histology we processed 1 to 2 sagittal sections per mouthpart, whereas for serial sectioning we processed approximately 250 sagittal sections per mouthpart. We also cultured the fungal organism from tadpole mouthparts for the detection of $B$. dendrobatidis, following methods previously described (Longcore et al. 1999). Briefly, culturing involved incubating small pieces of infected mouthpart on a $1 \%$ tryptone, antibiotic agar plate at room temperature. After $1 \mathrm{wk}$, sporangia were transferred to a $1 \%$ tryptone and agar plate and incubated at room temperature for 7 to $10 \mathrm{~d}$. Finally, a $1 \mathrm{~cm}^{2}$ piece of agar containing sporangia was placed in a $30 \mathrm{ml}$ flask of $1 \%$ tryptone broth and maintained at $4^{\circ} \mathrm{C}$.

Experimental infection via zoospore inoculation. To determine whether infection of Batrachochytrium dendrobatidis-free, wild-caught Rana muscosa tadpoles was possible, we collected 10 tadpoles from Kings Canyon National Park (KCNP) and housed them indi- 
vidually in plastic, aerated containers filled with $4 \mathrm{l}$ of carbon-filtered water at the animal care facility, University of California, Berkeley. Tank water was changed weekly and tadpoles were fed rabbit chow twice weekly. The water temperature was kept at $13^{\circ} \mathrm{C}$ and tadpoles received $12 \mathrm{~h}$ of light per day. Six of the containers received inoculations with $B$. dendrobatidis zoospores and the remaining 4 containers were used as controls. Tadpoles in the inoculated and control groups were of similar developmental stages (1.5 to $2.6 \mathrm{~cm}$ snout vent length [SVL], 0.7 to $3.3 \mathrm{~g}$ ) and had fully pigmented jaw sheaths and tooth rows at the start of the observation (see Fig. 1a).

Tadpoles were inoculated every 2 to $3 \mathrm{~d}$ over a period of 1 mo for a total of 12 inoculations. Fungal inoculum was prepared by spreading $1 \mathrm{ml}$ of Batrachochytrium dendrobatidis broth culture $(1 \%$ tryptone) on a $1 \%$ tryptone and agar plate and incubating for 7 to $10 \mathrm{~d}$ at room temperature. Inoculum was isolated by J. E. Longcore from a Rana muscosa tadpole collected in Mono County, California, USA (culture identification: JEL216). The plate was then flooded with $6 \mathrm{ml}$ of sterile, distilled water for 45 to $60 \mathrm{~min}$ to release zoospores (following Longcore et al. 1999). One $\mathrm{ml}$ of the $6 \mathrm{ml}$ zoospore solution was added directly into the water of each tadpole tank. On average, $9.0 \times 10^{5}$ zoospores were in each inoculation, measured using a hemacytometer. Control inoculum was prepared following the same methods but without $B$. dendrobatidis in the broth. To test for early infection, 2 chytrid-exposed tadpoles and 1 control were euthanized $4 \mathrm{wk}$ after the first inoculation. The remaining 4 tadpoles in the exposure group were inoculated 3 more times over the next week (total 15 inoculations) and then received no further inoculations. One of each of these 4 were euthanized at Weeks $7,19,20$, or 20 after the first inoculation. The 3 remaining control tadpoles were euthanized at Week 20 after the first inoculation.

To detect infection, standard histology was performed on 5 exposed tadpoles and all controls. As another method to detect infection, we cultured the fungus from 1 exposed tadpole euthanized at Week 20. Mouthparts of each tadpole were inspected and photographed once per week, beginning on the day of first inoculation until euthanasia. Based on the photographs and visual observations, we produced illustrations to summarize the pattern of pigment loss due to chytridiomycosis.

Experimental transmission from tadpoles to conspecifics. To determine whether conspecific transmission was possible within the larval stage, 5 Rana muscosa tadpoles with confirmed Batrachochytrium dendrobatidis infections were housed with 8 uninfected tadpoles (Developmental Stages 37 to 39; sensu Gos- ner 1960). The infected tadpoles were wild-caught from Yosemite National Park (YNP) and the uninfected tadpoles were wild-caught from KCNP. Infection status was assessed by visual inspection and cytology. The tadpoles were housed together in a container filled with $10 \mathrm{l}$ of carbon-filtered water and cared for in the same manner as the tadpoles exposed to $B$. dendrobatidis zoospores (described in the above section). To be closer to the optimal temperature for the fungus (17 to $23^{\circ} \mathrm{C}$ : Longcore et al. 1999, Piotrowski et al. 2004), the water temperature was maintained at $16^{\circ} \mathrm{C}$. Infected tadpoles were marked by a small notch made in their tails above the muscle to be distinguishable from the initially uninfected individuals.

To determine the onset of detectable infection, 2 exposed tadpoles were haphazardly selected from the tank each week for $4 \mathrm{wk}$. They were tested for Batrachochytrium dendrobatidis by visual inspection, cytology, and histology with serial sectioning. Four control tadpoles were housed together in a separate container. One control tadpole was removed and euthanized each week and tested for the fungal pathogen using the same tests applied to the exposed tadpoles.

To determine whether conspecific transmission was possible from the larval to postmetamorphic stage, 6 Batrachochytrium dendrobatidis-free, postmetamorphic Rana muscosa were housed individually with 5 tadpoles each. Four containers housed tadpoles that were infected with $B$. dendrobatidis and 2 contained uninfected tadpoles as controls. Postmetamorphic animals were wild-caught as tadpoles from KCNP, metamorphosed in the laboratory, and were 2.5 to $3.1 \mathrm{~cm}$ SVL at the beginning of the experiment. Infected tadpoles were wild-caught in YNP and were at Stages 34 to 39. Uninfected tadpoles were wild-caught from KCNP and were at Stages 30 to 36. Infection status of tadpoles was determined visually and confirmed with cytology. Each container was filled with 81 of carbonfiltered water and a platform was placed just above the water line for the postmetamorphic animal to rest. Animals were housed and fed in the same manner as the tadpoles exposed to $B$. dendrobatidis zoospores described above, with the addition of twenty 1 wk old crickets added each week as food for the postmetamorphic animal. Tank water temperature was maintained at $16^{\circ} \mathrm{C}$. Infection status of postmetamorphic animals was assessed at the beginning of the experiment and at Day 18 via cytology. Postmetamorphic animals and tadpoles were observed every 1 to $2 \mathrm{~d}$, and any mortality was recorded until the experiment ended on Day 96.

Identification of Batrachochytrium dendrobatidis in tadpoles. To verify whether the patterns of depigmentation seen in the laboratory were similar to those in the field, surveys were conducted in 2002 at 5 sites 
containing Rana muscosa populations in Yosemite, Sequoia, and Kings Canyon National Parks in the Sierra Nevada mountains of California, USA. Surveys consisted of catching tadpoles (up to 25), assessing developmental stage, and visually inspecting the mouthparts of each. B. dendrobatidis infection in each population was further investigated by testing a subset of the tadpoles caught ( $\mathrm{n}=1$ to 10 ) with cytology, histology with serial sectioning, and/or $B$. dendrobatidis culturing.

\section{RESULTS}

\section{Experimental infection via zoospore inoculation}

We successfully infected previously uninfected tadpoles in the laboratory. Of the 4 tadpoles that were exposed and held for $7+w k$, all 4 became infected with Batrachochytrium dendrobatidis; 3 infections were confirmed with standard histology and 1 by culturing the fungus from the tadpole mouthpart. In contrast, based on results from standard histology, no evidence of infection was found in the 2 exposed tadpoles that were euthanized after $4 \mathrm{wk}$ or in the 4 control animals. In histology and culture, fungal sporangia were not distinguishable from those previously described for B. dendrobatidis (Longcore et al. 1999, Pessier et al. 1999).

Loss of pigment was detected visually in the 4 infected tadpoles while no pigment loss was found in the 2 exposed tadpoles in which infection was not detected or in the 4 control tadpoles. Pigment loss was first detected at Week 7 after the first inoculation in 2 tadpoles, Week 11 in the third, and Week 15 in the fourth. The extent of pigment loss increased quickly after initial detection. By Weeks 20 to 21, the total area of the jaw sheath from which pigment had been lost in the 3 remaining infected animals was $45 \%, 90 \%$, and $98 \%$. There was no pigment loss in the tooth rows.

\section{Experimental transmission from tadpoles to conspecifics}

We confirmed transmission of Batrachochytrium dendrobatidis between infected and initially uninfected tadpoles using histology with serial sectioning; $B$. dendrobatidis infection was found in animals exposed for 3 and 4 wk but not in animals exposed for 1 and 2 wk. There was no pigment loss (visual inspection) in the animals exposed for 1 and $2 \mathrm{wk}$. One of the 2 infected animals removed at Week 3 showed very slight mouthpart abnormalities (5\% loss of upper jaw-sheath pigment, no loss of lower jawsheath pigment, and partially depigmented tooth rows) upon visual inspection. The animals from the first 3 wk were between Stages 37 and 40. The animals from Week 4 lost mouthpart pigmentation; however, because they were at Stages 41 to 42 , any pigment loss was likely due to metamorphic changes. Jaw-sheath scrapes (cytology) were negative for $B$. dendrobatidis. Controls were negative for $B$. dendrobatidis based on visual inspection (Weeks 1 to 3) and cytology (Weeks 1 to 4 ).

We confirmed transmission from the larval to postmetamorphic stage. All postmetamorphic animals were uninfected at the start of the experiment and the 4 animals exposed to infected tadpoles were infected on Day 18. The 2 controls were uninfected on Day 18. Three of the infected postmetamorphic animals were found dead on Day 39 and the fourth on Day 50. The 2 uninfected postmetamorphic animals were alive and clinically healthy on Day 96 when the experiment was ended. All 30 tadpoles (20 infected, 10 uninfected) remained alive until the end of the experiment and appeared clinically healthy.

\section{Identification of Batrachochytrium dendrobatidis in tadpoles}

Fig. 1a-d shows the general pattern of pigment loss caused by chytridiomycosis. Based on the above experiments and field surveys (discussed below), pigment loss began with 'gaps' (i.e. a complete loss of pigment in a localized area of the jaw sheath surrounded by fully pigmented areas; a discontinuity in the length of the beak pigment) in the jaw sheaths that became larger over time. Some infected tadpoles examined in the field had lost all jaw-sheath or tooth-row pigment. The general pattern elucidated from tadpoles exposed to a low temperature treatment $\left(4^{\circ} \mathrm{C}\right)$ is illustrated in Fig. 1e-h, based on descriptions in Rachowicz (2002) and field surveys (below). In contrast, this pattern began with a loss of tooth-row pigment and a continuous reduction in jaw-sheath pigment width until it was completely lost. Both patterns started with complete pigmentation (Fig. 1a,e) and ended with a loss of all mouthpart pigment (Fig. 1d,h).

Tadpoles exposed to a low temperature (Fig. 2a) or infected with Batrachochytrium dendrobatidis (Fig. 2b) showed histological differences that reflect the pigment loss patterns described above. After a winter at the bottom of a frozen lake (low temperature exposure), jaw-sheath cells had the same organization as fully pigmented jaw sheaths (Fig. 2a,c). However, after exposure to low temperature, fewer keratinized cells were seen in the jaw sheath, very few were pigmented, and no keratinized cells were seen in the tooth rows in the section shown. B. dendrobatidis-infected 

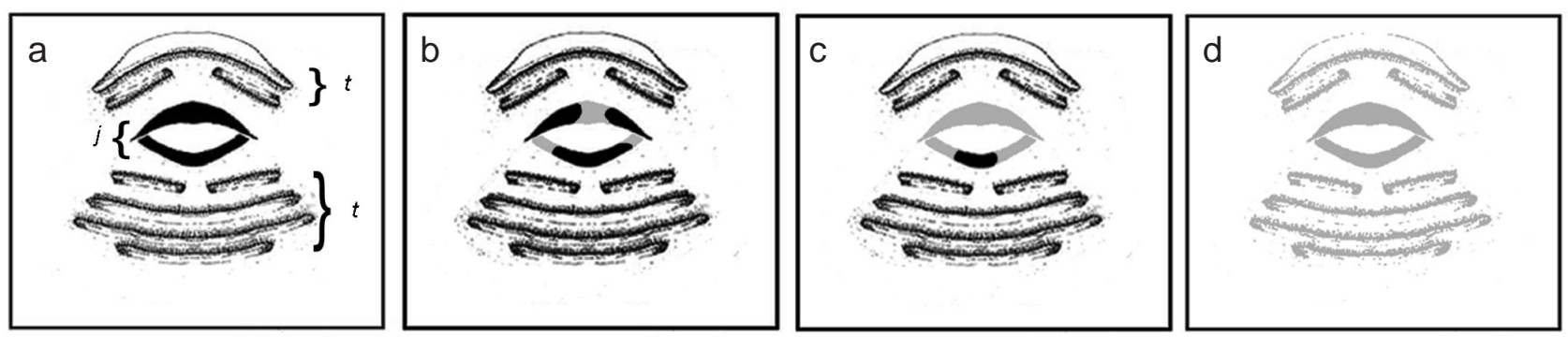

Infected with Batrachochytrium dendrobatidis
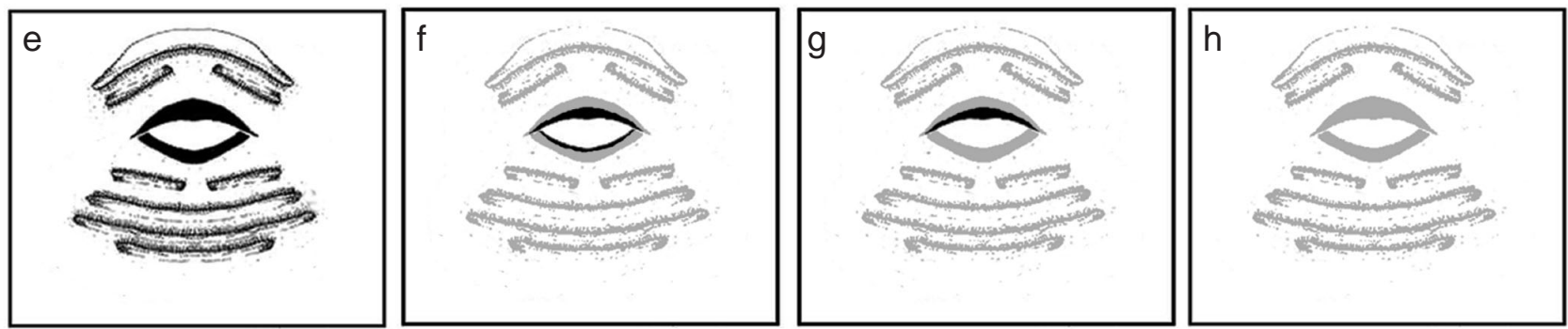

Low temperature

Fig. 1. Rana muscosa. Illustration of tadpole mouthparts showing 2 patterns of pigment loss over time. Upper (anterior) tooth rows $(t)$, upper and lower (posterior) jaw sheaths $(j)$, and 4 lower tooth rows $(t)$ are shown. Black is pigmentation and gray is loss of pigment. $(\mathrm{a}-\mathrm{d})$ The pattern of loss associated with Batrachochytrium dendrobatidis and $(\mathrm{e}-\mathrm{h})$ the pattern of pigment loss associated with a low overwintering temperature. Note that some $R$. muscosa tadpoles have 1 to 2 additional tooth rows anterior to the upper jaw sheath. The outline of the tadpole mouthparts is from Altig et al. (1998)
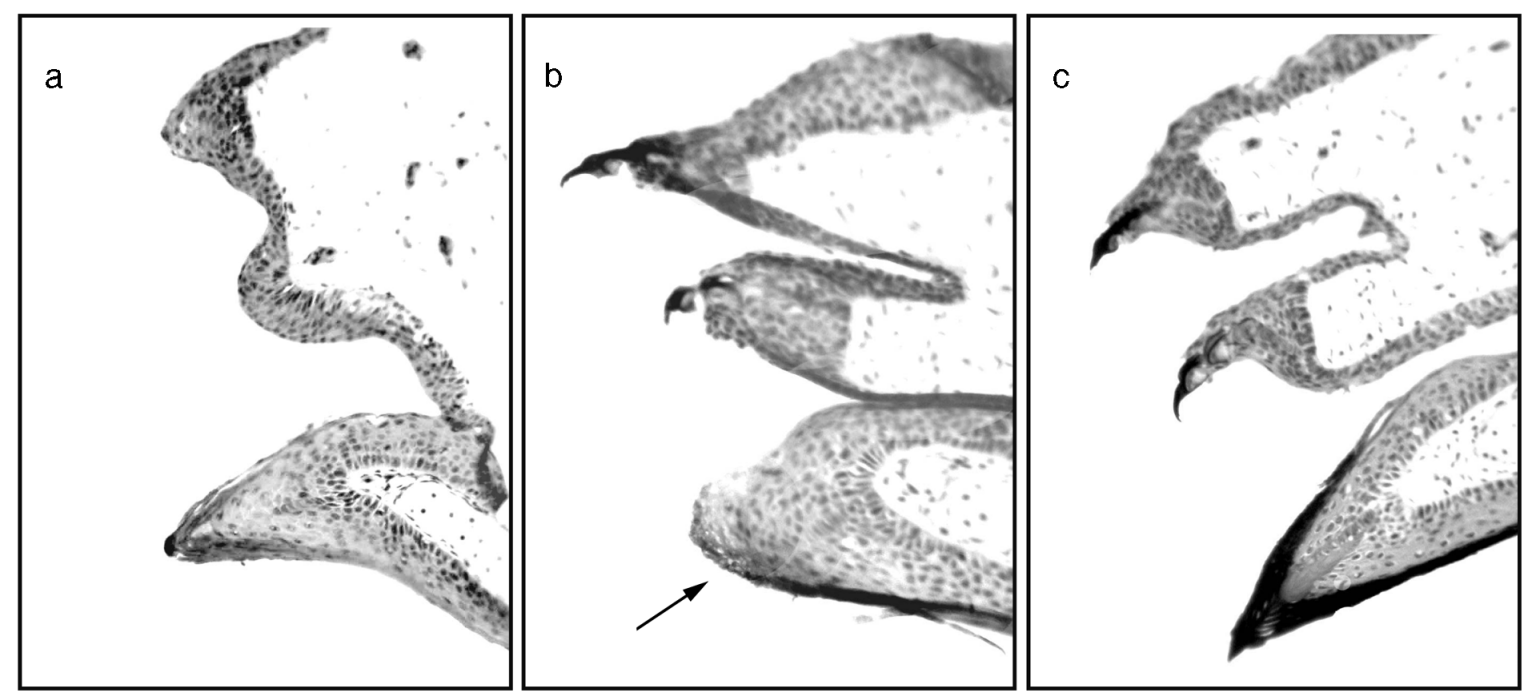

Fig. 2. Rana muscosa (a) Upper (anterior) jaw sheath and 2 upper tooth rows of a tadpole collected approximately $10 \mathrm{~d}$ after lake melt-out. Keratin is present in the jaw sheath but not in the tooth rows. The dark black on the end of the jaw sheath is the only pigmented keratin. (b) Upper jaw sheath infected with chytridiomycosis and 2 upper tooth rows. The jaw sheath contains numerous Batrachochytrium dendrobatidis sporangia (arrow). The dark black on the lower part of the jaw sheath and tooth rows is pigmented keratin. (c) Normal upper jaw sheath and 2 upper tooth rows. The dark black on the jaw sheath and tooth rows is pigmented keratin

jaw sheaths (Fig. 2b) displayed histological features similar to those previously described (e.g. hyperkeratosis: Fellers et al. 2001). In the mouthpart section shown, pigmentation was only seen on part of the infected jaw-sheath section, and upon visual inspection, this area appeared to be the beginning of a gap.

Our histological examinations of Rana muscosa tadpoles that were experimentally infected from conspe- 
cific tadpoles support the progression of the disease that is illustrated in Fig. 1a-d. We detected very early infection (after $3 \mathrm{wk}$ of exposure to infected tadpoles) using histology with serial sectioning; infection was discrete and localized within the jaw sheath, and few fungal sporangia were seen per section. After 4 wk of exposure, localized infections seen consisted of more sporangia and covered more area within the jaw sheath than Week 3 infections, and numerous localized infections had developed simultaneously within a jaw sheath. After 3 and $4 \mathrm{wk}$ of exposure, sporangia were present in 3 to $20 \%$ of the jaw sheaths (lengthwise) and all sections with infection were consecutive. Stained slides showed that full pigment was preserved in tadpoles without any infection or visual pigment loss (Fig. 2c).

Field surveys (Table 1) clearly showed 2 patterns of pigment loss in tadpoles: (1) low temperature-exposure pattern ('continuous') and (2) Batrachochytrium dendrobatidis-infection pattern ('gaps'). In a survey at Site 1, which was conducted approximately $10 \mathrm{~d}$ after ice melted from the surface in early June 2002, tadpoles had the low temperature pattern of pigment loss, and no evidence of $B$. dendrobatidis was found.

Sites 2 to 5 contained tadpoles with pigment loss (listed in order of progressing loss; Table 1) and confirmed Batrachochytrium dendrobatidis infections. Pigment was lacking in localized areas (gaps) of the jaw sheaths and/or an entire jaw sheath was missing pigment. When lack of pigment in the jaw-sheath length was large (>65\%), tooth rows also lost part of or all pigment.

\section{DISCUSSION}

Chytridiomycosis is clearly associated with population collapse in several species of declining amphibians (Berger et al. 1998, Daszak et al. 1999, Lips 1999, Bradley et al. 2002, Lips et al. 2003); however, not all infected populations and species are being negatively affected (Weldon 2002, Mazzoni et al. 2003). To understand the population and species level dynamics of chytridiomycosis, studies that focus on the transmission and effects of the disease on all life stages of the host are necessary. In our experiments, we demonstrated that Rana muscosa tadpoles can be infected by fungal zoospores and that tadpoles can transmit the infection to each other and to postmetamorphic animals. We also showed that infected tadpoles remained clinically healthy while infected postmetamorphic animals died. All uninfected animals remained alive during our experiments. This result is consistent with observations of tadpoles remaining at sites where postmetamorphic anurans infected with Batrachochytrium dendrobatidis were dead or dying (Berger et al. 1998, Bradley et al. 2002, Mazzoni et al. 2003).

The implications of the transmission of Batrachochytrium dendrobatidis from infected larval Rana muscosa likely go beyond this species. This study shows that transmission can occur between tadpoles and from tadpoles to postmetamorphic animals in one species, and thus raises the possibility that congregations of tadpoles may become extremely large reservoirs for the fungus, which might spread the disease to postmetamorphic animals. Our results can inform models

Table 1. Rana muscosa. Examination of tadpoles at sites in Yosemite (YNP) and Sequoia-Kings Canyon (SEKI) National Parks in 2002

\begin{tabular}{|c|c|c|c|c|c|c|c|}
\hline $\begin{array}{l}\text { Site } \\
\text { location }\end{array}$ & Date & $\begin{array}{c}\text { No. } \\
\text { examined }\end{array}$ & $\begin{array}{l}\% \text { with jaw- } \\
\text { sheath pig- } \\
\text { ment loss }\end{array}$ & $\begin{array}{l}\% \text { of jaw- } \\
\text { sheath pig- } \\
\text { ment lost }\end{array}$ & $\begin{array}{l}\text { Pattern of jaw- } \\
\text { sheath pig- } \\
\text { ment loss }\end{array}$ & $\begin{array}{l}\text { \% with } \\
\text { tooth-row } \\
\text { pigment loss }\end{array}$ & $\begin{array}{l}\text { No. tadpoles tested, type } \\
\text { of Batrachochytrium } \\
\text { dendrobatidis test, and } \\
\text { result (Gosner stage) }\end{array}$ \\
\hline 1-SEKI & 11 June & 23 & 100 & 0 or 50 & Continuous & 100 & $\begin{array}{l}4 \text { histology with serial } \\
\text { sectioning; } 4 \text { negative } \\
\text { (Stages } 31-35 \text { ) }\end{array}$ \\
\hline 2-YNP & 22 June & 13 & 62 & $3-13$ & Gaps & 8 & $\begin{array}{l}6 \text { histology with serial } \\
\text { sectioning, } 1 \text { culture; } 7 \\
\text { positive (Stages } 37-39 \text { ) }\end{array}$ \\
\hline 3-YNP & 16 July & 18 & 78 & $3-70$ & Gaps & 11 & $\begin{array}{l}6 \text { cytology, } 4 \text { histology } \\
\text { with serial sectioning; } 6 \\
\text { positive (Stages } 30-40 \text { ), } \\
4 \text { negative (Stages } \\
26-28 \text { ) }\end{array}$ \\
\hline 4-SEKI & 24 June & 15 & 100 & $45-80$ & Gaps & 100 & $\begin{array}{l}3 \text { cytology, } 5 \text { culture; } 8 \\
\text { positive (Stages } 33-40 \text { ) }\end{array}$ \\
\hline 5-YNP & 26 September & 11 & 55 & $65-99$ & $\begin{array}{l}\text { Gaps or no } \\
\text { pigment }\end{array}$ & 55 & $\begin{array}{l}1 \text { cytology; } 1 \text { positive } \\
\text { (Stage } 39 \text { ) }\end{array}$ \\
\hline
\end{tabular}


that predict the dynamics of the disease, in particular by highlighting the need to include stage-structure to reflect the biphasic lifestyle of anurans where the larval stage is clinically healthy yet can transmit the disease to conspecifics. Simple epidemiological models show that a primary determinant of the persistence of infection is the length of the infectious period (Anderson \& May 1991). Pathogens with short infectious periods do not tend to persist after an epidemic, whereas those with long infectious periods may be more likely to persist between epidemics (Keeling \& Grenfell 1998). Given this, a healthy life stage may allow a disease to persist even when it causes mortality in another life stage.

If infected tadpoles with long larval stages release zoospores over extended periods, long larval stages may increase the likelihood of outbreaks by preventing extinction of the fungal population. Bosch et al. (2001) found that in sympatric anurans in Spain, those with longer larval periods experienced severe epidemics while species with shorter larval periods did not. In the southwestern United States, Bradley et al. (2002) found chytridiomycosis in Rana yavapaiensis and speculated that the long larval period of this species may allow the pathogen to persist between observed seasonal outbreaks. Hopkins \& Channing (2002) also speculated that the long larval period of Afrana fuscigula in South Africa makes the frog more susceptible to chytridiomycosis. $R$. muscosa may be vulnerable to severe chytridiomycosis in part because the pathogen is sustained in tadpoles during their 2 to 4 yr larval stage. In colder, high-altitude tropical areas of Australia and Central America, where chytridiomycosis has been associated with population declines in numerous species (Berger et al. 1998, Lips et al. 2003), individuals generally have longer larval periods than those living in the lowland, warmer tropics (Morrison \& Hero 2003). Given the severity of population declines in these high-altitude regions, the role of larval-stage length in chytridiomycosis dynamics should be investigated. One notable exception is the American bullfrog $R$. catesbeiana; although it has a long larval period and both life stages become infected, adults retain a low level infection and seldom die (Bradley et al. 2002, Mazzoni et al. 2003). This example suggests that some species are less susceptible to the disease; species-specific innate immunity has been suggested as a factor (Carey et al. 2003).

In species where the postmetamorphic animals are clinically healthy, this life stage could function as a reservoir or carrier, infecting members of sympatric species or more susceptible members of the same species. Two widely introduced postmetamorphic amphibians, the African clawed frog Xenopus laevis (Weldon 2002) and the American bullfrog Rana catesbeiana
(Bradley et al. 2002, Mazzoni et al. 2003), can maintain Batrachochytrium dendrobatidis while remaining clinically healthy. Several native amphibians that now occur sympatrically with introduced bullfrogs have declined dramatically (Jennings \& Hayes 1994), raising the question of the role of interspecies transmission in these declines.

\section{Identification of Batrachochytrium dendrobatidis in tadpoles}

Detection of early Batrachochytrium dendrobatidis infection is dependent upon the identification technique used. In the laboratory, infection was identified by histology with serial sectioning after 3 wk of exposure to infected conspecifics. Given the localized nature of an early stage of infection, false negative results are likely unless serial sections are examined. The 2 zoospore-inoculated tadpoles in which no infection was found were euthanized early and examined by histology using 2 sections. They may have been at an early stage of infection and serial sectioning may have allowed the detection of localized infected areas. By the time gaps were visible in jaw sheaths of our zoospore-inoculated tadpoles, however, 1 or 2 sections were sufficient to detect chytridiomycosis.

To identify chytridiomycosis in the wild, simple, nonlethal detection techniques are necessary. Epithelial cell scrapes of tadpole mouthparts and postmetamorphic skin and visual inspection of tadpole mouthparts are possibilities (Berger et al. 1998, Fellers et al. 2001). In this study we detected Batrachochytrium dendrobatidis by identifying a specific pattern of pigmentation loss that can be distinguished from other types of loss in Rana muscosa, and confirmed B. dendrobatidis in animals with this pattern by other methods. Currently, an important weakness in chytridiomycosis research is the lack of a reliable, non-lethal diagnostic test that can confirm lack of infection.

Based on our findings, we recommend that visual inspections in Rana muscosa (1) take place at least $3 \mathrm{wk}$ after lake melt-out, (2) target older tadpoles (that have had a longer period to become infected), but those at less than Stage 41, and (3) focus on pigmentation gaps in the jaw sheaths. Although differences in the pattern of pigment loss between infection and prolonged low temperature exposure can be distinguished at many stages (Fig. 1b,c,e,f), mouthparts may look similar when jaw sheaths are fully depigmented (Fig. 1d,h); thus, surveys should not be conducted until mouthpart pigment has had sufficient time to return after the water temperatures warm. Older tadpoles may be more likely to be infected. At Sites 4 and 6 (Table 1), tadpoles showing pigment loss were primarily at 
Stages 35 to 40 , whereas tadpoles at Stages 28 to 32 had not lost pigment. This may be caused by longer exposure times and/or larger mouthparts providing a larger substrate for Batrachochytrium dendrobatidis zoospores to infect. Tadpoles begin to metamorphose at Stage 41 and mouthparts become naturally depigmented (Gosner 1960, Altig \& McDiarmid 1999); therefore, the techniques described in this paper should not be used on tadpoles that are beyond Gosner Stage 40 . Gaps in jaw-sheath pigment should be used as the primary indicator of chytridiomycosis. Tooth-row abnormalities are more uncertain as a means for detection because teeth can be difficult to see due to their small size and because aberrant and displaced tooth rows are common (Altig \& McDiarmid 1999). However, timing of tooth-row loss (Fig. 1) may be informative; tooth rows were lost after jaw-sheath pigment in many tadpoles with $B$. dendrobatidis and before jaw-sheath pigment in tadpoles exposed to low temperature.

Because mouthpart depigmentation that is not associated with chytridiomycosis has been reported in larval anurans, we recommend that visual inspections of mouthparts be corroborated with histological analysis or other techniques in voucher specimens when possible. Exposure to DDT and corticosterone induce a regression of tissue (a 'hole') that results in a complete loss of the upper mouthparts (Hayes et al. 1997). Additionally, bullfrog tadpoles exposed to coal-ash pollution during egg development had a significantly higher frequency of some portion of at least one tooth row missing than those that developed in an unpolluted pond (Rowe et al. 1998). Mouthpart loss in R. muscosa caused by chemical pollution has not been investigated.

Others have found tadpole mouthpart abnormalities at sites where postmetamorphic animals are experiencing chytridiomycosis-related die-offs (hylids and centrolenids: Lips 1999, Lips et al. 2003; ranids: Fellers et al. 2001, Lips et al. 2004). However, researchers have not found abnormal tadpole mouthparts in some locations where the postmetamorphic animals are infected with Batrachochytrium dendrobatidis (Bufo canorus: Green \& Sherman 2001; B. boreas: Muths et al. 2003; Rana yavapaiensis: Bradley et al. 2002). Whether B. dendrobatidis infects the tadpoles in these species is unknown. When chytridiomycosis was first recognized in Australia, abnormal mouthparts were not seen (Berger et al. 1999); however, pigmentation loss has recently been found in several Australian species (D. Mendez \& P. Symonds pers. comm.). Visual inspection is probably relevant to other species, but investigations of the association between $B$. dendrobatidis infection and mouthpart pigment loss in other species should be conducted to verify the usefulness of visual inspection as a widescale detection technique.
Acknowledgements. This work was funded by the NIH National Institutes of Environmental Health Sciences, Ecology of Infectious Diseases program (grant R01 ES12067-01), and grants from the Canon National Parks Science Scholars Program, the Cleveland Zoological Society, and the Department of Integrative Biology, University of California, Berkeley. We are grateful to M. Daugherty, E. Knight, M. Stice, and T. Tunstall for excellent field and laboratory support and C. Briggs, M. Hoopes, R. Knapp, J. Morgan, J. Parker, $\mathrm{M}$. Wake, and anonymous reviewers for useful comments. We thank P. Ustach for providing the initial illustrations of tadpole mouthparts, and D. Mendez and P. Symonds for personal communications. We especially thank J. E. Longcore for teaching us proper culturing technique and providing a fungal isolate. All animal procedures were approved by the Animal Care and Use Committee, University of California, Berkeley, USA.

\section{LITERATURE CITED}

Altig R, McDiarmid RW (1999) Body plan: development and morphology. In: McDiarmid RW, Altig R (eds) Tadpoles: the biology of anuran larvae. University of Chicago Press, Chicago, p 24-51

Altig R, McDiarmid RW, Nichols KA, Ustach PC (1998) A key to the anuran tadpoles of the United States and Canada. Contemporary Herpetology Information Series 2 (www.cnah.org/ch/chis/1998/2)

Anderson RM, May RM (1991) Infectious diseases of humans: dynamics and control, 1st edn. Oxford University Press, New York

Berger L, Speare R, Daszak P, Green DE and 10 others (1998) Chytridiomycosis causes amphibian mortality associated with population declines in the rain forests of Australia and Central America. Proc Natl Acad Sci 95:9031-9036

Berger L, Speare R, Hyatt A (1999) Chytrid fungi and amphibian declines: overview, implications and future directions. Environment Australia, Canberra

Blaustein AR, Hokit DG, O'Hara RK (1994) Pathogenic fungus contributed to amphibian losses in the Pacific Northwest. Biol Conserv 67:251-254

Bosch J, Martinez-Solano I, Garcia-Paris M (2001) Evidence of a chytrid fungus infection involved in the decline of the common midwife toad (Alytes obstetricans) in protected areas of central Spain. Biol Conserv 97:331-337

Bradford DF (1989) Allotopic distribution of native frogs and introduced fish in high Sierra Nevada lakes of California: implications of the negative impact of fish introductions. Copeia 1989:775-778

Bradford DF, Tabatabai F, Graber DM (1993) Isolation of remaining populations of the native frog, Rana muscosa, by introduced fishes in Sequoia and Kings Canyon National Parks, California. Conserv Biol 7:882-888

Bradley GA, Rosen PC, Sredl MJ, Jones TR, Longcore JE (2002) Chytridiomycosis in native Arizona frogs. J Wildl Dis 38:206-212

Carey C, Pessier AP, Peace AD (2003) Pathogens, infectious disease, and immune defenses. In: Semlitsch RD (ed) Amphibian conservation. Smithsonian Books, Washington, DC, p 127-136

Daszak P, Berger L, Cunningham AA, Hyatt AD, Green DE, Speare R (1999) Emerging infectious diseases and amphibian population declines. Emerg Infect Dis 5: 735-748

Fellers GM, Green DE, Longcore JE (2001) Oral chytridio- 
mycosis in the mountain yellow-legged frog (Rana musCosa). Copeia 2001:945-953

Gosner KL (1960) A simplified table for staging anuran embryos and larvae with notes on identification. Herpetologica 16:183-190

Green DE, Sherman CK (2001) Diagnostic histological findings in Yosemite toads (Bufo canorus) from a die-off in the 1970s. J Herpetol 35:92-103

Grinnell J, Storer T (1924) Animal life in the Yosemite. University of California Press, Berkeley, CA

Hayes TB, Wu TH, Gill TN (1997) DDT-like effects as a result of corticosterone treatment in an anuran amphibian: is DDT a corticoid mimic or a stressor? Environ Toxicol Chem 16:1948-1953

Hopkins S, Channing A (2002) Chytrdiomycosis in Northern and Western Cape frog populations, South Africa. HerpDigest 3:334-336 (www.herpdigest.org)

Jennings MR (1996) Status of amphibians. In: Sierra Nevada ecosystem project: final report to Congress, Vol 2. Assessments and scientific basis for management options. University of California, Centers for Water and Wildland Resources, Davis, p 921-944

Jennings MR, Hayes MP (1994) Amphibian and reptile species of special concern in California. California Department of Fish and Game, Inland Fisheries Division, Rancho Cordova

Keeling MJ, Grenfell BT (1998) Effect of variability in infection period on the persistence and spatial spread of infectious diseases. Math Biosci 147:207-226

Knapp RA, Matthews KR (2000) Non-native fish introductions and the decline of the mountain yellow-legged frog from within protected areas. Conserv Biol 14:428-438

Laurance WF, McDonald KR, Speare R (1996) Epidemic disease and the catastrophic decline of Australian rain forest frogs. Conserv Biol 10:406-413

Lips KR (1998) Decline of a tropical montane amphibian fauna. Conserv Biol 12:106-117

Lips KR (1999) Mass mortality and population declines of anurans at an upland site in western Panama. Conserv Biol 13: $117-125$

Lips KR, Green DE, Papendick R (2003) Chytridiomycosis in wild frogs from southern Costa Rica. J Herpetol 37:215-218

Lips KR, Mendelson III JR, Munoz-Alonso A, CansecoMárquez L, Mulcahy DG (2004) Amphibian population declines in montane southern Mexico: resurveys of historical localities. Biol Conserv 119(4):555-564

Editorial responsibility: Peernel Zwart,

Utrecht, The Netherlands
Longcore JE, Pessier AP, Nichols DK (1999) Batrachochytrium dendrobatidis gen. et sp. nov., a chytrid pathogenic to amphibians. Mycologia 91:219-227

Mazzoni R, Cunningham AA, Daszak P, Apolo A, Perdomo E, Speranza G (2003) Emerging pathogen of wild amphibians in frogs (Rana catesbeiana) farmed for international trade. Emerg Infect Dis 9:995-998

Morrison C, Hero JM (2003) Geographic variation in lifehistory characteristics of amphibians: a review. J Anim Ecol 72:270-279

Muths E, Corn PS, Pessier AP, Green DE (2003) Evidence for disease-related amphibian decline in Colorado. Biol Conserv 110:357-365

Nichols DK, Lamirande EW, Pessier AP, Longcore JE (2001) Experimental transmission of cutaneous chytridiomycosis in dendrobatid frogs. J Wildl Dis 37:1-11

Pessier AP, Nichols DK, Longcore JE, Fuller MS (1999) Cutaneous chytridiomycosis in poison dart frogs (Dendrobates spp.) and White's tree frogs (Litoria caerulea). J Vet Diagn Invest 11:194-199

Piotrowski JS, Annis SL, Longcore JE (2004) Physiology of Batrachochytrium dendrobatidis, a chytrid pathogen of amphibians. Mycologia 96:9-15

Rachowicz LJ (2002) Mouthpart pigmentation in Rana muscosa tadpoles: seasonal changes without chytridiomycosis. Herpetol Rev 33:263-265

Rowe CL, Kinney OM, Congdon JD (1998) Oral deformities in tadpoles of the bullfrog (Rana catesbeiana) caused by conditions in a polluted habitat. Copeia 1:244-246

Vredenburg VT (2004) Reversing introduced species effects: experimental removal of introduced fish leads to rapid recovery of a declining frog. Proc Natl Acad Sci 101: 7646-7650

Vredenburg VT, Summers AP (2001) Field identification of chytridiomycosis in Rana muscosa (Camp 1915). Herpetol Rev 32:151-152

Weldon C (2002) Chytridiomycosis survey in South Africa. Froglog 51:1-2

Wright KM, Whitaker BR (2001) Amphibian medicine and captive husbandry. Krieger Publishing, Malabar

Young BE, Lips KR, Reaser JK, Ibanez R and 10 others (2001) Population declines and priorities for amphibian conservation in Latin America. Conserv Biol 15:1213-1223

Zweifel RG (1955) Ecology, distribution and systematics of frogs of the Rana boylii group. Univ Calif Publ Zool 54: 207-292

Submitted: March 7, 2004; Accepted: June 21, 2004

Proofs received from author(s): September 14, 2004 